\title{
The Pathogenesis and Epidemiology of Klebsiella pneumoniae
}

One fascinating aspect of the field of hospital infection control is that the subject appeals to, and involves, so many different people from the health sciences. Clinicians, epidemiologists, microbiologists, nurses, administrators, educators, and pharmacologists are but some of those whose combined efforts are crucial for prevention of cross-infection.' Effective programs for control may involve all of the persons listed above, and more. In addition, our search for new understanding about the forces and issues involved depend on development of new information both on the ward and at the laboratory bench.

A second feature is the international character of the contributors to the field. Interest in this topic has spread to most continents, and investigators from many nations have aided the prevention of this almost-universal concern. ${ }^{2.3}$

Enabling professionals from these several areas of expertise and from different areas of the world to get together to share information has been a continuing problem. Each discipline has its own professional and scientific meetings to attend, and the overlap between the groups is not great enough for most to meet together often. Some progress has been made. International Conferences on Nosocomial Infection Control have been sponsored by a number of organizations. ${ }^{4-7}$ For several years, the Association for Practitioners in Infection Control has been holding joint sessions with the Society of Hospital Epidemiologists of America (SHEA) at the former group's Annual Educational Conference; members of each organization (and many participants belong to both) are invited to submit their work for presentation and discussion. Joint educational meetings have been held between SHEA and the Hospital Infection Society, whose members reside primarily in the United Kingdom or on the European continent.

Of all these groups, however, the American Society of Microbiology (ASM) has perhaps the most enviable record of getting different professionals together. This organization annually provides at least two interdisciplinary meetings that attract many of the persons active in hospital infection control from around the world. Both the Interscience Conference on Antimicrobial Agents and Chemotherapy (held in the fall) and the ASM Annual Meeting (held in the spring), attract large numbers of registrants from around the world. The two meetings provide forums for both clinical and other microbiologists to discuss data with others interested in hospital crossinfection. These efforts are spurred by the Nosocomial Infections Division of the ASM, whose members join together with those from other ASM divisions to organize a variety of slide and poster presentations as well as seminars relevant to hospital infection control.

The articles that follow were presented at such a seminar at the 83rd Annual Meeting of the ASM in New Orleans in March 1983. The session was organized by Anita Highsmith and Sally Jo Rubin, and focused on Klebsiella pneumoniae, an organism of great concern to all who deal with nosocomial infection.

The unique ecological niche occupied by this organism is discussed by Bagley; she highlights the microbiologic mix of organisms that we now find comprises what historically has been regarded as the single species Klebsiella pneumoniae. Rubin then presents an excellent and succinct summary of the various marker methods used for epidemiologic and clinical studies of the organism. Epidemiologic patterns of Klebsiella in the hospital are reviewed by Jarvis and colleagues, followed by O'Brien and his co-workers reminding us of the clinical relevance of the antimicrobial resistance of Klebsiella. Highsmith and Jarvis conclude by discussing a number of virulence factors that may contribute to the laboratory and clinical features previously discussed.

The seminar is characteristic of those presented at the ASM Annual Meeting in that it deals with clinically important issues and presents basic, clinical, and epidemiologic information at one forum. Highsmith and Rubin have put together a seminar well worth the reading for those who must deal with Klebsiella in the ward or in the laboratory-and this must encompass virtually all readers of this journal.

\section{REFERENCES}

1. Phillips DF: Growing pains-Infection control practice shifts to encompass variety of disciplines. Hospitals $1983 ; 84(3): 80-85$.

2. Velimirovic B: Hospital infections from the WHO perspective. Infert Control 1983; 4:364-366.

3. Western KA, St John RK, Shearer I.A: Hospital infection contmolAn international perspective. Infert Control 1982; 3:453-455.

4. Dixon RE (ed): Second International Conference on Nosocomial Infections. Am / Med 1981; 70:379-473,631-744, 899-986.

5. Sacks T, McGowan JE Jr (eds): International Symposium on Control of Nosocomial Infection. Rer Infert Dis 1981:3:635-807.

6. Wenzel RP (ed): First International Symposium on HospitalAcquired Infections. Infect Control 1983; 4:363-397

7. Wenzel RP (ed): First International Symposium on HospitalAcquired Infections. Infert Control 1984; 5:18-43.

John E. McGowan, Jr., MD Emory University School of Medicine Director, Clinical Microbiology Grady Memorial Hospital Atlanta, Ceorgia 